\title{
Benefit 'myths'? The accuracy and inaccuracy of public beliefs about the benefits system
}

\author{
Ben Baumberg Geiger
}

\section{Contents}

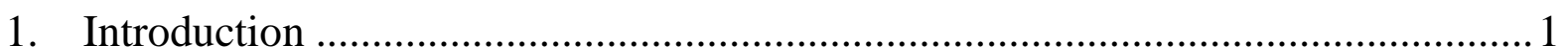

1.1 What the public knows ....................................................................... 2

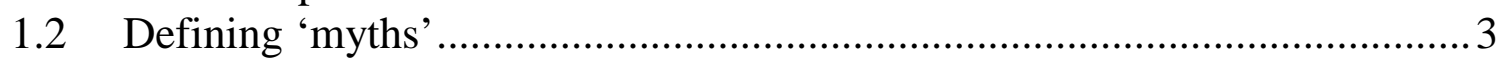

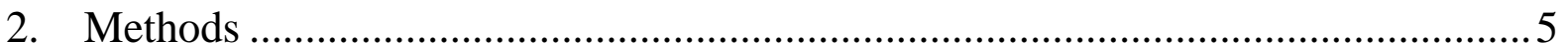

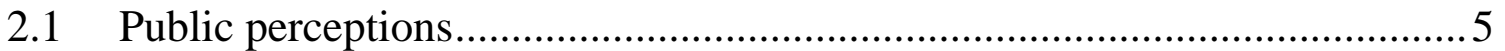

2.2 Measuring 'myths' ..........................................................................

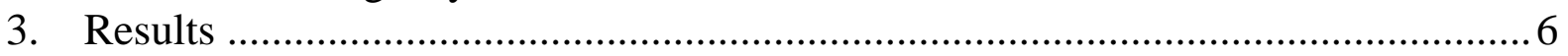

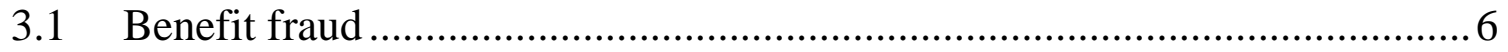

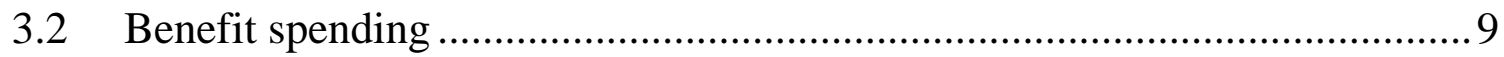

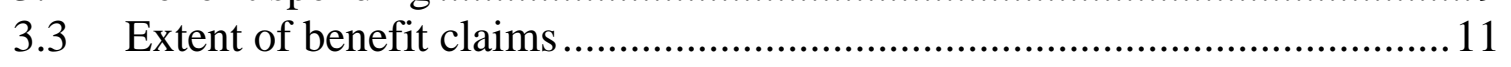

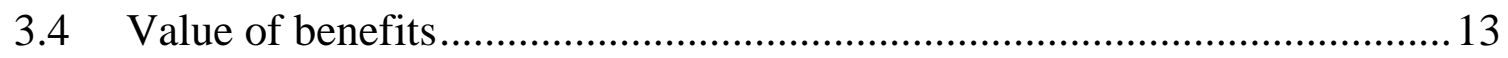

3.5 Other beliefs: better off in work, JSA durations, and 'welfare tourism' .....16

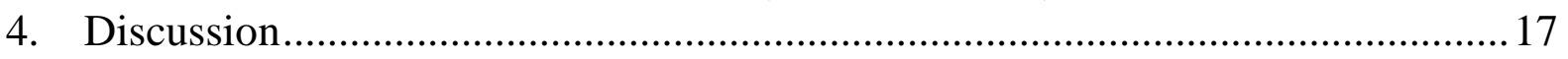

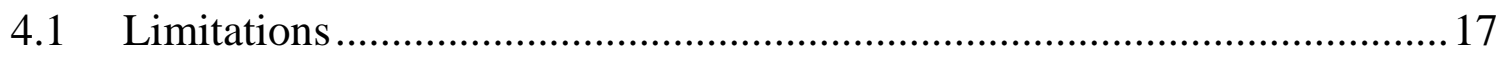

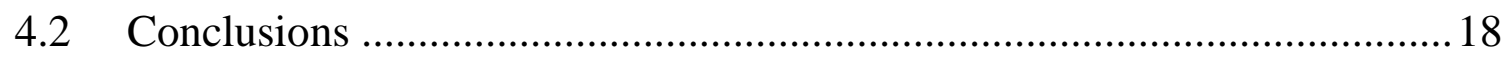

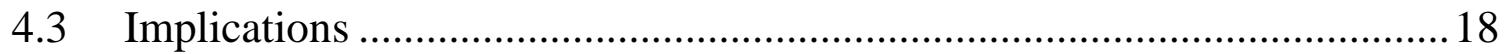

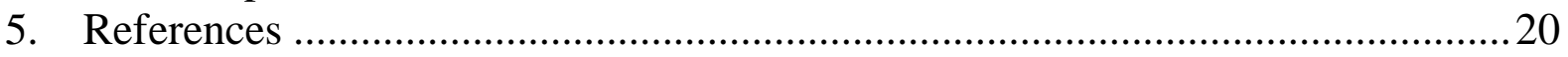

CASE/199

October 2016
Centre for Analysis of Social Exclusion

London School of Economics

Houghton Street

London WC2A 2AE

CASE enquiries - tel: 02079556679 


\section{Centre for Analysis of Social Exclusion}

The Centre for the Analysis of Social Exclusion (CASE) is a multi-disciplinary research centre based at the London School of Economics and Political Science (LSE), within the Suntory and Toyota International Centres for Economics and Related Disciplines (STICERD). Our focus is on exploration of different dimensions of social disadvantage, particularly from longitudinal and neighbourhood perspectives, and examination of the impact of public policy.

In addition to our discussion paper series (CASEpapers), we produce occasional summaries of our research in CASEbriefs, and reports from various conferences and activities in CASEreports. All these publications are available to download free from our website. Limited printed copies are available on request.

For further information on the work of the Centre, please contact the Centre Manager, Jane Dickson, on:

Telephone: $\quad \mathrm{UK}+2079556679$

Fax: $\quad$ UK+20 79556951

Email:_j.dickson@lse.ac.uk

Web site: http://sticerd.lse.ac.uk/case

(C) Ben Baumberg Geiger

All rights reserved. Short sections of text, not to exceed two paragraphs, may be quoted without explicit permission provided that full credit, including (C) notice, is given to the source. 


\title{
Editorial note
}

Ben Baumberg Geiger is a Senior Lecturer in Sociology and Social Policy at the University of Kent. He was based within CASE from 2006 to 2011, and completed his $\mathrm{PhD}$ at CASE in 2011 under the supervision of John Hills and Tania Burchardt (see http://etheses.lse.ac.uk/192/).

Particular thanks to Bobby Duffy and Charlotte Saunders at Ipsos MORI for insightful comments as well as invaluable data, and to Declan Gaffney and Kate Bell for collaborating on the initial work that led to this project. Thanks too to the other survey agencies (NatCen, ESS, YouGov) and sponsors (Elizabeth Finn Care/turn2us, TUC, RSS, Kings College London, the European Commission, and multiple other sponsors of BSA \& ESS).

\begin{abstract}
There is a widespread assumption that increasingly negative public attitudes to the benefits system are due to 'myths' held by the British public. However, there is little prior research on whether the public believe these 'myths', nor critical scrutiny of benefit 'truths'. This paper therefore investigates what British people believe about the benefits system, and the extent to which these beliefs can be regarded as correct. To do this, we use 46 measures from 18 datasets, and compare these perceptions to true figures obtained from a variety of sources.
\end{abstract}

We find that - against expectations - there are some areas where people misperceive the benefits system in ways that do not seem likely to lead to harsh attitudes, or where the public are (on average) relatively accurate. Yet overall, our evidence shows that the British public do have low levels of understanding of the benefits system, primarily in ways that seem likely to undermine public support. People wildly overestimate unemployment benefits compared to pensions, and also overestimate how much unemployment claimants without children receive. Half of people believe that out-of-work benefit claims have risen in the past fifteen years, whereas they have fallen noticeably. And while it is difficult to know the true level of benefit fraud exactly, the public overestimate fraud compared to any reasonable figure. We conclude by discussing the implications for both understanding and changing attitudes towards benefits.

Key words: benefits, social security, public attitudes, myths

JEL number: I380

Corresponding author: b.b.geiger@kent.ac.uk 


\section{Introduction}

Current debates about the benefits system in Britain conventionally start from two assumptions. The first assumption is that public attitudes towards benefit claimants have become much harsher in recent decades, a view which can be overstated, but in general terms is borne out by the evidence (Baumberg, 2014). The second assumption is that this harshness is partly due to 'myths' that the British public hold about the benefits system (for a typical if well-expressed commentary, see Beresford, 2013). 'Mythbusters' have therefore been produced by campaigning organisations ranging from inter alia the TUC (2013), a coalition of churches (Baptist Union of Great Britain et al., 2013), and think-tanks ranging from the political left (Coote and Lyall, 2013) to the right (Taunton-Collins, 2013). ${ }^{1}$ Academics have similarly critiqued myths, such as 'Broken Britain' (Slater, 2012), 'families with three generations have never worked' (MacDonald et al., 2013, Macmillan, 2011) and 'workless communities' (MacDonald et al., 2014), while LSE Professor John Hills recently subtitled his new book 'the welfare myth of them and us' (Hills, 2014).

Yet while these mythbusters have fact-checked claims by politicians and the media (itself an important role, to which we return in the Conclusion), there has been almost no academic study on whether the public actually believe these 'myths' about the benefits system. This is despite burgeoning academic literatures on public knowledge in other domains, particularly political knowledge (Carpini and Keeter, 1996, Bullock et al., 2013), but also economics (Blinder and Krueger, 2004), inequality (Kuziemko et al., 2015), ethnicity, and migration (Alba et al., 2005, Herda, 2010). In contrast, there are only a handful of academic studies over the past thirty years that examine benefits knowledge in Britain, and even these only cover a small subset of the key issues (Taylor-Gooby et al., 2003, Golding and Middleton, 1982). Moreover, across many of these fields of knowledge there is an absence of critical scrutiny about the 'truth' that is contrasted to these 'myths'. This is particularly surprising given the uncertainty inherent in the social scientific enterprise (e.g. Flvybjerg, 2001); sometimes these claimed 'truths' are themselves wrong, and at extremes 'mythbusting' can be a way of asserting particular viewpoints as the truth, as we shall see.

In this paper, we therefore investigate both the British public's perceptions of the benefits system, and how far - and how certainly - we can describe these perceptions as 'true' or 'false'. To investigate 'truths', we have used an eclectic range of sources detailed below. To investigate public perceptions, we conduct new analyses using eighteen datasets across six survey series, including several that are being made available for wider academic study for the first time (via www.benbaumberg.com/benefitmyths). Before describing our methods in more detail, we look more closely at previous studies of policy-relevant knowledge, and define what we mean by a 'myth'.

${ }^{1}$ For the purposes of transparency, we should note that we have been involved in one of these 'mythbusters'. 


\subsection{What the public knows}

It is a badly-kept secret that the public has poor aggregate levels of knowledge about science, social science and politics. In Philip Converse's words (1975), "the most familiar fact to arise from sample surveys is that popular levels of information about public affairs are, from the point of view of an informed observer, astonishingly low" (cited by Carpini, 2000:132). To take some typical examples: less than half of Britons or Americans know that the earth goes around the sun once per year (Durant et al., 1989); most people cannot name their local elected representative (Carpini, 2000); and many cannot even provide an estimate of key economic quantities like inflation at all, much less provide a correct one (TNS Opinion \& Social, 2010). While it has been argued that people are often most accurate about phenomena they come into contact with (Taylor-Gooby et al., 2003:17), there are other studies showing widespread inaccuracies in what we might term 'experiential' (rather than 'learned') knowledge. For example, people systematically over-estimate the proportion of ethnic minorities (Alba et al., 2005), people born abroad (Herda, 2010), homosexuality (Martinez et al., 2008), and teenage pregnancy (Duffy, 2009).

However, the literature on benefits knowledge is much smaller. A few US studies look at knowledge of Social Security and find that the public are (on average) roughly accurate in terms of the average Social Security benefit check (Blinder and Krueger, 2004) and who qualifies for Social Security (Barabas, 2012). However, they are inconsistent in their knowledge of detailed program rules and tend to overestimate the incentive to work (Liebman and Luttmer, 2012), and while the perception that Social Security will be running deficits in future is accurate (Blinder and Krueger, 2004), the extent to which it is correct to say that the system will go 'bankrupt' is debatable (Barabas, 2012). Greater inaccuracies are found for food stamps, which are perceived to be a far greater cost to Government than they actually are (Jacobs and Shapiro, 1999, CNN, 2011), and there is little published research on beliefs about other aspects of welfare. In the UK, there is only one relevant peer-reviewed study within the past fifteen years (although there are also several non-academic polls, as we review below). This finds that many people are aware that the benefits system is one of the largest parts of public spending, but most wrongly think that unemployment benefits cost the state more than pensions (Taylor-Gooby et al., 2003).

This superficially suggests a varying level of accuracy across different domains of knowledge, but the actual level of ignorance is far worse than this - for even where the public are correct on average, this does not mean that most people individually are correct. Kulinski et al's (2000) influential study of US welfare knowledge finds that the public on average over-estimated the amount spent on welfare, the average welfare payment, and the proportion of people claiming welfare, but under-estimated the proportion of claimants who had been on welfare for $8+$ years, and were actually correct about the proportion who were African-American. Yet because these averages balance out different kinds of wrong answers among individuals, they found that "on none of the individual items did a majority, or close to it, get the fact right" (p797). The prior evidence from other countries and on other topics does not necessarily 
suggest that the public will consistently be biased towards negative misperceptions about benefits, but it does suggest that a widespread lack of knowledge is likely. We examine both aspects of this in our analysis below.

\subsection{Defining 'myths'}

It is important to begin by teasing apart the multiple common meanings of 'truth' and 'myth'. While one meaning covers narrow truths about the world that are directly testable (which we might term 'narrow facts'), another refers to deeper truths that lie beneath direct observation (which we might term 'worldviews'), including 'truth' in a religious sense. Societal debates - including those about the benefits system - will exist on both of these levels of simultaneously, and claims of 'truth' and 'myth' will likewise occur in both. The Secretary of State for Work and Pensions, Iain Duncan Smith MP, can say that "I have no hesitation in claiming that Britain is broken. This claim is factual" (in Slater, 2012:962), and Slater can describe this as a 'myth', and in both cases we accept their statements as legitimate uses of language, even though the claim is not directly about a testable proposition. It is not the aim of these paper to present a new theory of the complex relationship between narrow facts and broader worldviews (which mirrors the conventional distinction between attitudes/beliefs and values, e.g. Sundberg, 2014:4.1); for our purposes, it is sufficient to note that worldviews are generally not amenable to social scientific investigation other than through the narrow facts that they are messily entangled with, and as such we restrict our focus here to 'benefit myths' conceived on the level of factual statements.

Even having excluded this wider meaning, the idea of classifying a piece of knowledge as a 'fact' - "an item of correct information, one that accurately represents the real world" (Kuklinski et al., 1998:147) - is nevertheless contentious. This is partly the ontological problem that there is no value-free way of expressing factual statements, but the primary difficulty is epistemological: even if there is a truth (within a particularly value-laden way of seeing the world), our knowledge of this truth is never certain. So-called facts lie on a continuum of uncertainty, in which "some purported facts are more indisputably correct than others" (Kuklinski et al., 1998:148). Any claims that the public is 'ignorant' of a given fact must come alongside a consideration of the extent to which our knowledge of this fact is certain, and inevitably involves a subjective judgement on the part of the speaker as where the boundary between reasonable and unreasonable interpretations lies.

Implicit in the accusation that the public believes 'benefit myths' is a further value judgement that such ignorance is undesirable. A common view is that ignorance is damaging to democracy, for if the public are not sufficiently well-informed, then this sharply reduces their capacity to vote according to their interests, and more generally harms their capacity to hold elected officials to account (Converse, 1964, Carpini and Keeter, 1996). However, people cannot be fully informed about everything, given limited cognitive capacities and the costs of acquiring information, and voters may still be 'competent' if they are instead guided by heuristics, values, and media/elite cues (in ways that have been long-debated by political scientists; see Barabas, 2012, 
vs. Lupia, 2006). The question is what subset of knowledge should be considered important for the public to know, if any; as Kuklinski et al (1998:147) put it, "to a great extent, the criteria for and relevance of political facts are determined within, not outside, politics."

Moreover, it is clear that the public's accuracy will vary according to the facts that are chosen. There are some areas in which the public are accurate; American's perceptions of issues such as the level of the minimum wage, median incomes and the prevalence of college degrees are 'surprisingly accurate' (according to Blinder and Krueger, 2004), while Taylor-Gooby et al (2003) found for their set of questions on the British welfare state more broadly that "the most striking aspect of public perceptions is their accuracy". It is not just the case that overestimates and underestimates can balance out so that the public are on average quite accurate, but individual accuracy can likewise be common: Delli Carpini's exhaustive review of US polls shows that accuracy across 112 domestic policy items varies from $6 \%$ to $96 \%$ (Carpini and Keeter, 1996:80-81). It is obviously not the case that no-one knows anything about anything - nor is it reasonable to expect everyone to know everything about every issue. In our analysis, we therefore review every measure of benefit beliefs from British data that we have been able to obtain, leaving our judgement as to their respective relevance to the Conclusion. 


\section{Methods}

This study aimed to review the British public's accuracy of knowledge about the benefits system in the recent past (2000-2015). This requires two interlinked sets of analyses - one of public perceptions, another of the truth of the benefits system which we describe in turn.

\subsection{Public perceptions}

To investigate public perceptions, we decided to go beyond a review of the academic/grey literature to instead conduct new analyses of all the datasets that we could gain access to. We did this partly because beliefs data in some high-quality survey series have not previously been analysed. Primarily, though, original analyses were necessary in order for us to look at the proportion of responses that are 'correct' (defined as per the following section), rather than simply looking at average responses. After reviewing publicly available databases and contacting private survey agencies and sponsoring charities for access to their data, we obtained eighteen different datasets across six different survey series.

While full details of the surveys are given in Web Appendix 1, they can be grouped into three levels of robustness. Firstly, the British Social Attitudes surveys (BSA, 10 waves) and the European Social Survey (ESS) are high-quality, face-to-face surveys using (complex) random samples from the Postcode Address File. Secondly, we use online panels from both Ipsos MORI (2 waves) and YouGov (2 waves). Finally, we use face-to-face surveys that use less robust sampling techniques: an Ipsos MORI face-to-face survey (based on a high-quality quota sample within randomly selected areas) and the European Commission's survey Eurobarometer (EB, 2 waves). In quality terms these are likely to lie between the online panels and full random surveys. Basic descriptive characteristics of each survey are shown in Web Appendix 2.

These sampling differences must be borne in mind when interpreting the results below. Online panels are increasingly used in social research and generally show similar distributions of political variables to face-to-face surveys using random samples, but we would expect the samples to be slightly skewed towards those with greater political interest/knowledge (Sanders et al., 2007, Liu and Wang, 2014). Levels of knowledge from the online panels are therefore likely to be upper bounds on population values, and the results should not be treated as unquestionable 'facts' about public knowledge, but rather as the best estimate of such knowledge that is presently available.

\subsection{Measuring 'myths'}

As the discussion above makes clear, to define the 'correct' response we must make a subjective judgement about the boundaries of reasonable beliefs, given inherent uncertainty about the truth. We explain this case-by-case below. For questions where 
respondents are asked to state a percentage of the population, however, we adopt a general rule of using windows of ten percentage points around the correct value (or from $0-10 \%$, if the true value is lower than $5 \%$ ). While arbitrary, this allows respondents some margin for error, and seems reasonable given respondents' propensity to round their answers to the nearest $5 \%$ or $10 \%$.

\section{Results}

\subsection{Benefit fraud}

Overestimates of benefit fraud are perhaps the most commonly cited 'benefit myth'. They are also an instructive case with which to begin, because whether these are indeed 'myths' is more complex to answer than it might appear.

Five different survey questions have been asked about fraud. Mostly these ask explicitly about fraud and then clarify that this is people 'deliberately deceiving' the Government (the question labelled A1 in Table 1), or 'dishonestly claiming' (A4, A5). However, BSA (A2-A3) asked about 'falsely claiming', which is likely to capture a slightly broader concept than fraud. Questions also differ in whether they ask about fraud as a percentage of claims vs. as a percentage of spending, and which benefits they talk about, variously 'out-of-work benefits', 'welfare', 'unemployment benefits' and 'disability benefits'. (For the wording of all questions, see Web Appendix S3).

The British public's responses to these numeric questions are shown in Table 1 . There are statistically significant differences in levels of perceived fraud between the different questions, although whether these are due to the question, the survey mode or the sample is unclear: for example, 'false claiming' in BSA is perceived to be higher than fraud in the other surveys, but this might be because the more representative sample in BSA captures more people who believe fraud to be higher. Still, we can say with relative confidence that false claiming is perceived to be slightly higher for unemployment benefits than disability benefits, as these questions were asked to the same people (in BSA 2007). Overall, people thought that $29-37 \%$ of claims were fraudulent or false, and $24-27 \%$ of spending was on false claims. (Medians are lower than means, with the average person saying they thought 25-35\% of claims and $20 \%$ of spending was fraudulent). 
Table 1: Accuracy of public perceptions of the benefits system (continuous variables)

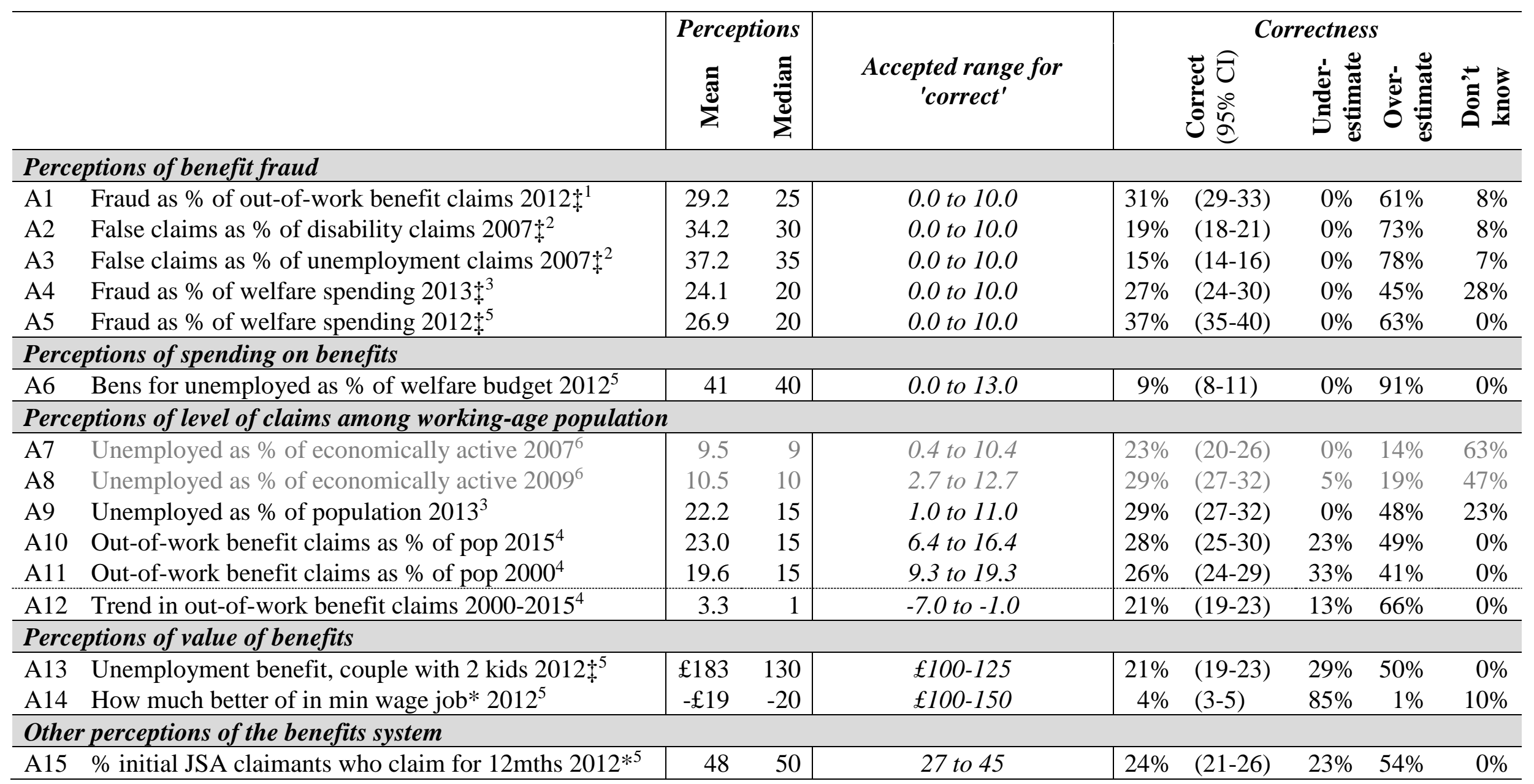

* Major / ¥ Minor issues around the 'true' figure given - see text \& Web Appendix 4

Source/mode: ${ }^{1} 2012$ MORI/F2F; 22007 BSA/F2F; ${ }^{3} 2013$ MORI/web; ${ }^{4} 2015$ MORI/web; ${ }^{5} 2012$ YouGov/web; ${ }^{6}$ Eurobarometer/phone. 
The 'mythbusters' above often compare this to the official Government fraud estimates, and conclude that the British public wildly overestimate the level of fraud. But it is not that simple. Firstly, some people's definition of fraud is different from the definition enshrined in law. For example, a substantial minority of unemployment benefit claimants are unwilling to take literally any low-status, badly-paid job (Lindsay and McQuaid, 2004). It seems unreasonable to count this as 'fraud' - nearly all claimants want to work, such choosiness is shared in wider society (Dean and Taylor-Gooby, 1992:93-96, Dunn, 2010), and besides, it is unclear whether claimants would be able to get these jobs - but some respondents may be defining this as 'fraud'. (Indeed, a majority agree that 'around here, most unemployed people could find a job if they really wanted one' (Baumberg, 2014)).

Prompted by such a debate with the present authors, Ipsos MORI 2013 cleverly followed up question A4 by asking respondents to specify what they had understood as 'fraud'. Sizeable minorities of people described it as 'having more children so that they are entitled to more benefits' (35.1\% of those giving an answer), 'people claiming benefits who haven't paid any taxes/national insurance' (36.5\%), and 'people from abroad/immigrants claiming benefits' (46.1\%), with a majority (61.6\%) giving one of these responses - none of which are usually legally defined as fraud. While these responses were not as common as the behaviours that are legally defined as fraud, and these views in themselves can be seen as misperceptions of a sort, we should note that some of the divergence between perceptions and reality may be a matter of mismatched definitions.

Secondly, the official Government estimates are likely to be underestimates, because fraud is an inherently difficult concept to measure. This is not to suggest that the Government does this badly. In 2012/13, a random sample of 26,000 cases were reviewed, initially collating information from various Government and local authority sources before interviewing the claimant at their home (see Web Appendix 4). The Government infers that fraud is taking place either if fraud is then investigated further and proved in court, or if the claimant terminates or changes their claim shortly after the interview, and where there is 'a strong reason to deduce' that this was because of the fraud-checking process. This is best practice internationally, and was the only aspect of Government fraud management that was praised in an otherwise critical report (Gee et al., 2010:9). The resulting fraud estimates are indeed much lower than average fraud perceptions, varying between $0.3 \%$ of spending on incapacity benefits to $3.9 \%$ of spending on Carer's Allowance, which if anything are lower than estimated fraud in private sector insurance (Viaene and Dedene, 2004:318).

Yet inevitably some fraud will go undetected, particularly cash-in-hand earnings (Dean and Taylor-Gooby, 1992), but also some organised fraud. There is therefore no definitive truth, but it goes too far to say that 'there are no reliable figures on benefit fraud' (Taunton-Collins, 2013). Instead, we can specify the grounds on which we (subjectively) divide reasonable from unreasonable perceptions of fraud. Given the difficulty in inferring 'fraudulent intent', it seems unreasonable to consider a perception to be false if it is close to the estimate for fraud and claimant error 
combined (see Web Appendix 4). In assessing correctness, we allow people a ten percentage point window (as above), which means that it is not possible for anyone to be classified as underestimating fraud.

From this, we classify $27-37 \%$ of respondents as correct in the three most specific questions (which falls to $15-19 \%$ correctness in the BSA questions, if we treat 'false claims' as equivalent to fraud). In two of these surveys, $61-63 \%$ overestimated the level of fraud and $<10 \%$ said they did not know; in the third survey (MORI web 2013), $45 \%$ gave overestimates and $28 \%$ were 'don't knows'. It is worth adding that it is not the case that most people thought most claimants were fraudulent - the average person in all three surveys felt that fraud was restricted to no more than a quarter of benefits claims/spending.

In other words, a substantial minority of people accurately perceive the level of benefits fraud, but most people give overestimates. Further evidence for such misperceptions comes from the National Benefit Fraud Hotline 2009-10, where $<5 \%$ of calls led to claim being regarded as either fraud or error (FullFact, 2011). It is perhaps no surprise that the Government themselves have similarly accepted that "public perceptions of fraud in the benefit system do not reflect the situation" (HM Government, 2014, Appendix 1).

\subsection{Benefit spending}

Rather than assess the exact number of billions spent on the benefits system - which would primarily test the public's probably poor knowledge of the size of public spending in real terms - recent surveys have focused on the public's understanding of the relative size of different aspects of public spending. The true answer is harder to estimate than it may appear: terms like 'benefits for the unemployed' are broader than just Jobseeker's Allowance, also including portions of other benefits such as Housing Benefit (a reason why Taunton-Collins, 2013 critiques some of the 'mythbusters'). Nevertheless, adding portions of these other benefits is possible, and this is an area where there is more certainty than when looking at benefit fraud (see Web Appendix 4). 
Table 2: Accuracy of public perceptions of the benefits system (categorical variables)

\begin{tabular}{|c|c|c|c|c|c|c|c|}
\hline & & Year (source) & Correct answer(s) & Correct & Incorrect & $\mathbf{D K}^{\mathbf{1}}$ & $\boldsymbol{n}$ \\
\hline \multicolumn{8}{|c|}{ Perceptions of spending on benefits } \\
\hline B1 & Largest area of government spending & 2001 (BSA F2F) & Benefits & $31.3 \%$ & $64.5 \%$ & $4.2 \%$ & 3275 \\
\hline B2 & 2nd largest area of govt spending & 2001 (BSA F2F) & Education, health & $44.8 \%$ & $49.8 \%$ & $5.4 \%$ & 3275 \\
\hline B3 & 2-3 biggest areas of government spending & 2013 (MORI web) & Health, pensions, benefits & $9.1 \%$ & $80.0 \%$ & $10.9 \%$ & 1015 \\
\hline B4 & Smallest area of govt spending & 2001 (BSA F2F) & Housing, transport, aid & $49.0 \%$ & $47.1 \%$ & $3.9 \%$ & 3275 \\
\hline B5 & Largest area of social security spending & 2001 (BSA F2F) & Retirement pensions & $27.0 \%$ & $69.3 \%$ & $3.8 \%$ & 3275 \\
\hline B8 & Which costs more, JSA or state pension? & 2013 (MORI web) & Pensions & $46.5 \%$ & $40.4 \%$ & $13.1 \%$ & 1015 \\
\hline B9 & Which policy would save most? & 2013 (MORI web) & Raising pension age & $16.4 \%$ & $63.7 \%$ & $19.9 \%$ & 1015 \\
\hline B10 & Which policy would save least? & 2013 (MORI web) & TV / bus for pensioners & $51.4 \%$ & $28.2 \%$ & $20.4 \%$ & 1015 \\
\hline \multicolumn{8}{|c|}{ Perceptions of level of claims among working-age population } \\
\hline B11 & Unemployment as \% of active population & 2010 (YouGov web) & 8 percent & $27.3 \%$ & $51.6 \%$ & $21.1 \%$ & 992 \\
\hline
\end{tabular}


Within public spending as a whole, social security is the largest single component and this is moderately well-known. (Questions that ask respondents to choose the correct answer from a list of categories, as in this case, are shown in Table 2). In 2001, around half (49\%) of people thought that social security benefits were one of the top two areas of government spending (with 31\% knowing that it was the highest), with very few (2\%) thinking it was the area of lowest spending (B1, B2, B4). A more recent question similarly found that around half (52\%) thought that working-age benefits and/or state pensions were one of the 2-3 largest areas of public spending (B3). Knowledge of other areas of public spending is more inconsistent: only $26 \%$ did not manage to name any of the top 2-3 areas of spending, yet only $9 \%$ managed to name all of working age benefits, state pensions, and health (B3).

Within the social security budget, though, levels of knowledge deteriorate. Only 27\% of people knew that retirement pensions were the largest area of spending in 2001, with far more people (44\%) saying that unemployment benefits were greater (B5-7). More recently, and when given a straight choice, people were split as to whether Jobseeker's Allowance or state pensions were more expensive (B8). To put this in context, state pensions cost around ten times as much as unemployment benefits throughout this period. The same picture of overestimating unemployment benefits and underestimating pensions comes from a variety of other questions, whether on the share of the 'welfare budget' that goes on unemployment benefits (A6), how much raising the state pension age would save (B9), and other YouGov surveys for which the microdata are unavailable (Cooke, 2013:39, Kellner, 2015). Even accepting that the unemployment benefit costs are slightly underestimated (see Web Appendix 4), the public's average perceptions seem wildly inaccurate.

Perceptions of levels of spending on other areas of the benefits system are more inconsistent. Only 4\% in 2001 said that benefits for disabled people were the most expensive part of the social security system, and over $40 \%$ thought they were the least expensive, even though this was the second-largest area of spending behind pensions (B5-7). At the same time, one of the highest levels of correctness for any question came when people were asked which of a number of policy options would save the least money. Over half of respondents correctly said that stopping free bus travel or free TV licences for better-off pensioners would save the least, with only $28 \%$ giving a wrong answer (most commonly the spare room subsidy/bedroom tax), with $20 \%$ 'don't knows' (B10). It is therefore unfair to say that the public know nothing about benefit spending. However, there seems to be a continuing and considerable misperception about the relative costs of unemployment benefits and state pensions.

\subsection{Extent of benefit claims}

There are two obvious explanations for why people may overestimate spending on unemployment benefits - either people overestimate the number of claimants, or they overestimate the amount such claimants receive. The 'true' extent of benefit claims is relatively straightforward to estimate, although the extent of unemployment 
(irrespective of whether people are claiming benefits) is subject to greater uncertainty as it is based on survey responses (see Web Appendix 4). There are also widespread misunderstandings about what the 'unemployment rate' refers to, as it conventionally expresses unemployment as a share of the economically active rather than the working-age population as a whole.

A number of surveys have looked at perceptions of the level of unemployment per se, but some of these (A7-8) have poorly designed questions that result in half or more of respondents giving 'don't knows'. Ignoring these questions, the average respondent estimated that the unemployment rate as a share of the active population was $12 \%$ in 2010, and as a share of the total working-age population was 15\% in 2013 and 2024\% in 2008 (B11, A9 and B12 respectively). Similarly, the average respondent estimated that long-term sickness and disability was $15-19 \%$ of the working-age population in 2008 (2c.4). Despite the variation in these responses across surveys, and noting some uncertainty about the 'true' values (as above), these are all noticeably higher than the best estimates of the actual figures ( $8 \%, 6 \%, 4 \%$ and $6 \%$ respectively), echoing past overestimates found in Golding \& Middleton (1982). This suggests that people do indeed tend to over-estimate the level of unemployment and long-term sickness/disability.

However, when we look across all benefits (using a question kindly run by Ipsos MORI after conversations with the authors), the average respondent thinks that $15 \%$ of the working-age population claimed out-of-work benefits in 2015 (A10). This is perhaps surprisingly accurate (the true figure is $11.4 \%$ ), particularly given that unemployment itself is so overestimated. Indeed, the median perception of unemployment plus long-term sickness in ESS is at least 30\%, ${ }^{2}$ double the perceived level of out-of-work benefits in the Ipsos MORI poll. This may be for methodological reasons. Respondents are likely to be swayed by the response options presented to them (Schwarz, 1999), and so the extensive sequence of high response options presented in ESS may bias respondents to higher estimates. Alternatively, ESS may be more nationally representative than the other surveys that are liable to be biased towards more knowledgeable respondents (as above). Other possibilities are that because many unemployed/disabled people do not claim benefits, we should not expect these to match exactly; or that some people may correctly perceive the level of out-of-work benefit claims but still misperceive the relative balance of unemployment vs. other types of benefit claim (as also suggested by B12-13).

In terms of accuracy, and despite these varying concepts, question wordings, and survey samples, we consistently see that only a minority (19-30\%) - a considerable one, but still very much a minority - of the British public give a (roughly) correct answer to any of these questions. In nearly all cases the incorrect responses were over-estimates of the levels of unemployment, sickness/disability or out-of-work benefit claims. It is nevertheless worth highlighting that in 2015, a substantial

2 Responses to the ESS questions B12 and B13 are in five-point bands (e.g. 5-9\%); the combined figure sums the bottom of each band, and is therefore a lower bound on the perceived total. 
minority (23\%) underestimate the level of out-of-work benefit claims. Underestimates have not previously been possible (the true proportions were so close to zero that low answers were treated as correct), but where they become possible then they are likely to exist, even where the average person's answer is relatively accurate.

Finally, we can also look at perceived trends in out-of-work benefit claims (A10A12). Overall, the average respondent in 2015 thought that benefit claims had risen fractionally since 2000, in contrast to administrative data showing they have fallen noticeably (from $14.3 \%$ to $11.4 \%$ of the working-age population). However, there was a large spread of responses, with $34 \%$ perceiving a fall in benefit claims over time, $16 \%$ no change, and $50 \%$ perceiving a rise. If we define 'correct' as a decline of roughly the correct size (from a minimum of a one percentage point decline to a maximum of seven percentage points, half the initial level), then only $21 \%$ are correct, with $66 \%$ over-estimating the trend (i.e. thinking that claims have stayed the same or risen), and 13\% under-estimating it (i.e. thinking that claims have fallen by more than they actually have). The fall in out-of-work benefit receipt is not a widely-perceived phenomenon.

\subsection{Value of benefits}

The other simple explanation for misperceiving spending on unemployment benefits is that people over-estimate how much each claimant receives. This would be part of the wider 'myth' of benefit generosity referred to in many of the mythbusters. The actual evidence that people believe this 'myth', however, is much more nuanced.

The main evidence comes from the BSA using an indirect method. Initially, people are asked whether someone whose 'only income comes from state benefits' has enough to live on, given their personal situation (e.g. 'a 25-year old unemployed woman living alone). People are then given the true amount, and then asked again whether this person has enough to live on. Those people who change their response to say that the person is actually harder-up than they thought are treated as overestimating the true benefit, while those who change their response to say that the person is living more comfortably than they thought are treated as underestimating it.

Not only do these questions allow us to compare understanding of different types of benefits (the questions variously ask about carers, unemployed people, and pensioners, varied by family type), but we can also look at changes in understanding from 1994-2013. ${ }^{3}$ There are however two caveats. Firstly, no information is given on how the 'true' values given in BSA are derived. When we check these values, we find that most of them are accurate, but some of them depend on debatable assumptions, and a few are simply wrong (see Web Appendix 4); we draw attention to these where relevant below. Secondly, this question will give a lower bound estimate for people's

\footnotetext{
${ }^{3}$ BSA actually has similar questions dating back to 1986, but there are problems the earlier series see Web Appendix 3.
} 
misperceptions, as some misperceptions will not be sufficiently large to change people's feeling about whether benefits are enough to live on.

Bearing this in mind, the results are shown in Table 3 (trends in beliefs about whether benefits are enough to live on are analysed in Baumberg, 2014). As the 'mythbusters' claim, there are indeed some benefits that people tend to overestimate. For unemployment benefits for a single woman and for a childless couple in recent years, noticeably more people ( $8-11 \%$ more and $27-28 \%$ more people respectively) overestimate the benefit than underestimate it. This seems to be the case for most years in which this question has been asked, although for the unemployed single woman in 1994 (the earliest year available), people were as likely to underestimate as overestimate the benefit. Overestimates were also found in studies that ask people to give a figure for the level of benefits, including a family with two children on Supplementary Benefit in the late 1970s (Golding and Middleton, 1982), and the couple rate of unemployment benefit in 2012 (A13, notwithstanding the problems of establishing the true figure; see Web Appendix 4). 
Table 3: Accuracy of public perceptions of the value of benefits (British Social Attitudes, various years)

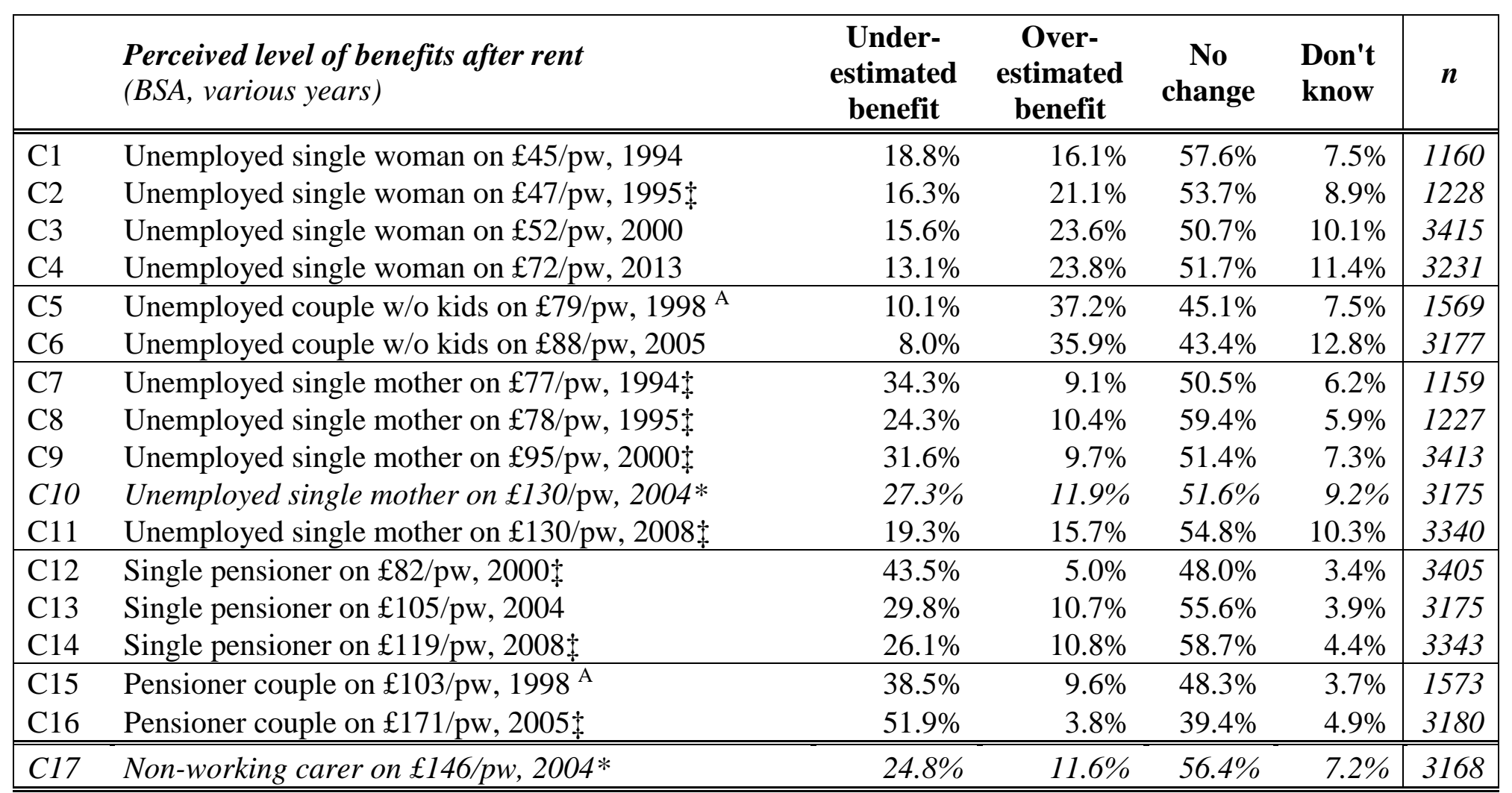

* = Major Issues around the 'true' figure - see text \& Web Appendix 4

A Slightly different wording ('married couple' in 1998, rather than 'couple living together' in 2005) 
Contrary to widespread assumptions, though, people did not systematically overestimate the levels of other types of benefits - indeed, in general they systematically underestimated them, believing that benefits were in fact lower than they really are. This was the case for:

Carers in 2005, although the 'true' figure here is contentious (although not strictly 'wrong'; see Web Appendix 4).

Unemployed single mothers for most years (1994-2004), where 14-25\% more people overestimated than underestimated the benefit (falling to $4 \%$ in 2008). This is a particularly striking finding when we consider that the BSA 'true' figures arbitrarily excluded Child Benefit and are therefore even lower than claimants would actually receive (see Web Appendix 4).

> Pensioners 1998-2008, with 15-48\% more people overestimating than underestimating the level of benefits for both pensioner couples and single pensioners. This does not mean that most people thought pensions were too generous; even after hearing the true value, respondents were still far more likely to say that pensioners were 'hard up' or 'really poor' than had 'more than enough to live on' (29-64\% vs. 2-11\% respectively, analyses not shown). But it does show that the assumption that most people systematically overestimate the level of state benefits is wrong.

It is possible to summarise this by saying that people tend to overestimate unemployment benefits, but considerably underestimate support to pensioners and unemployed families. Yet alongside this, it is striking just how variable people's perceptions are. In most cases, sizeable minorities of people were both underestimating and overestimating the level of benefits (and as noted previously, the question design means that these are lower bounds on misperceptions). If we look at the single question that asks people to give the exact value of unemployment benefits for a couple (A13, and noting the issues over the true value in Web Appendix 4), then over $10 \%$ estimate this as less than half of the actual value, and over $10 \%$ estimate this to be more than twice the actual value. As Philip Converse famously put it when describing political knowledge (in Barabas, 2012), public knowledge has a low mean but a high variance.

\subsection{Other beliefs: better off in work, JSA durations, and 'welfare tourism'}

Several of the mythbusters talk about the 'myth' that people are better-off on benefits than in-work (an argument that dates back to the principle of 'lesser eligibility' in the 1834 Poor Law and beyond), which depends on perceptions of incomes both out-ofwork and in-work. There is some evidence that people do underestimate in-work incomes; a DWP report using similar questions to the previous section (Kelly, 2008) finds considerable underestimates of how much government support a two-parent twochild family with one earner would receive. 
Similarly, a TUC mythbuster (using B14) claims that only 21\% of people know that an unemployed couple with two children would be better-off if one of them worked $30 \mathrm{hrs} / \mathrm{wk}$ at the minimum wage. However, the claimed 'true figure' here of $£ 138 / \mathrm{wk}$ better off (see A13) is probably an over-estimate, partly because the TUC seem to have slightly over-estimated how much better-off people would be in work (we make this $£ 128$ ), but more importantly because this figure excludes other costs and income losses that people would face in taking up employment (see Web Appendix 4). While it still seems likely that this unemployed couple would be better-off in work (and 'better-off calculators' are a standard part of welfare-to-work support), the extent that perceptions match reality is difficult to estimate in the absence of further information.

While less commonly discussed than the issues above, we can also look at people's perceptions of the duration of unemployment benefit claims. The public's average (mean) estimate of the proportion of Jobseeker's Allowance claims last for at least a year is 48\% in 2012 (in A15) and 38\% in 2015 (Kellner, 2015). However, the 'true' value claimed in the initial TUC mythbusting is $28 \%$, whereas Kellner claims it is $10 \%$. The latter claim in particular is debatable - it ignores JSA claimants who temporarily leave JSA but return to claim - with more plausible figures being either $32 \%$ or $40 \%$ (see Web Appendix 4). If we allow five percentage points either side of this as 'correct' (in A15), then 24\% are correct, with 23\% giving underestimates and $54 \%$ giving overestimates. This seems to be an area of ignorance rather than misperception (perhaps unsurprisingly given that it is not much-discussed in public debate), with the responses being almost randomly spread from 0 to 100 .

Finally, two YouGov polls (neither of which we have access to) have looked at perceptions of 'welfare tourism' (Kellner, 2015, Kellner, 2014). A full analysis of these would require a broader analysis of wider perceptions of migration. Still, it is worth noting that people overestimate the proportion of benefit claimants who are migrants, and they do this about fivefold to tenfold (even given uncertainty over some of the true figures). The mythbuster from the political right (Taunton-Collins, 2013) therefore seems correct to describe the idea that 'immigrants sponge off welfare' as 'scare-mongering'.

\section{Discussion}

\subsection{Limitations}

In talking about 'truths' and 'myths', it is necessary to be clear about the limitations of our analysis. Firstly, there is always a risk of non-response bias in sample surveys, and such biases are likely to be greater for the online panels that we include in our review. However, previous studies suggest that online samples will be biased to more knowledgeable respondents, and the public may therefore be even less informed than our results suggest. Secondly, our findings may not strictly reflect 'ignorance'. There is evidence that monetary incentives increase respondents' accuracy and decrease their partisan bias (Prior and Lupia, 2008, Bullock et al., 2013), and misperceptions may 
therefore reflect a lack of effort on the part of the respondent to provide accurate responses, with apparent 'beliefs' instead being justifications of politicised attitudes.

Finally, we unfortunately do not have unchallengeable 'facts' to which we can compare the public's views - much as this is often the way that mythbusters have been framed. Still, uncertainty is not the same as an absence of knowledge. In evaluating the accuracy of the public's beliefs about the benefits system, we make a judgement - necessarily subjective, but both transparent and grounded in the best available evidence - as to what the 'truth' is, and how close to this truth a respondent has to be to be counted as 'correct'. Given the wider context of encouraging better quantitative social science among academics, students and the wider public (a movement we are involved in through the Kent Q-Step Centre), we hope that the information in this paper will enable readers to interrogate the facts for themselves, rather than simply defer to them.

\subsection{Conclusions}

While the idea that the British public believe negative 'myths' about the benefits system is widespread, there is little previous evidence as to what the public believe, and even less as to whether such beliefs are accurate. Using 46 measures across 18 different datasets, this paper has shown - against such expectations - that there are some areas where people misperceive the benefits system in ways that do not seem likely to lead to harsh attitudes. In particular, people tend to underestimate the value of benefits for pensioners and unemployed people with children. A substantial minority (nearly one in four) also underestimate the level of out-of-work benefit claims. And there are even some areas about which the public are (on average) relatively accurate. For example, the average person is surprisingly accurate in knowing the share of the population who currently claim out-of-work benefits.

Yet overall, this paper has shown that the authors of 'mythbusters' are correct. Knowledge about the benefits system is low, as even where the public are right on average, on almost no measure do more than one-third of individuals provide a correct answer as we define it. And the public are often not right on average. People wildly overestimate unemployment benefits (which they have increasingly negative attitudes towards; Baumberg, 2014) compared to pensions, and overestimate how much unemployment claimants without children receive. Half of people believe that out-ofwork benefit claims have risen in the past fifteen years, whereas they have fallen noticeably. And while it is difficult to know the true level of benefit fraud exactly, the public overestimate fraud compared to any reasonable figure.

\subsection{Implications}

The implicit - and often explicit claim (TUC, 2013, Hills, 2014) - in most of the mythbusters is that these myths drive negative attitudes towards benefit claimants. However, it is difficult to test empirically whether this is true. We know that people interpret new evidence in ways that support their existing beliefs (Bolsen et al., 2014, 
Taber et al., 2009), which makes it difficult to confirm that beliefs are really driving attitudes, rather than vice versa. Elsewhere, we show that many - but not all - of these beliefs are associated with the view that benefit claimants are undeserving, even after controlling for people's political affiliations (Baumberg Geiger, In Press). Based on this, and wider experimental evidence, we argue that it seems likely that people's attitudes are linked (if in a complex way) to beliefs (Baumberg Geiger submitted). However, there is a large caveat here: there is far more to getting public support for the benefits system than simply mythbusting - those times (e.g. post-war Britain) and places (e.g. Nordic countries) in which the public see benefit claimants as more deserving are not necessarily characterised by accurate perceptions of benefits, and the evidence suggests mythbusting itself is unlikely to consistently produce strong changes in attitudes (see Baumberg Geiger, In Press). The role of benefit myths in public attitudes should not be overstated, yet neither should it be denied.

Finally, this leads us back to the 'mythbusters' with which we began. It is clear that politicians and the media do encourage the public to misperceive the benefits system (see Baumberg et al., 2012) - ignorance, like knowledge, is socially produced (Slater, 2012). Moreover, untruthful claims in elite debate are damaging in their own right, for they undermine democratic debate (see the discussion of Converse 1964 above). The actors best placed to tackle this are the UK Statistics Authority (via changes to their Code of Practice for Statistics) and public providers of benefit statistics (not least the DWP), and the recommendations in Baumberg et al (2012:88-89) therefore apply here. But to the extent that the providers of statistics are unwilling to take steps to improve public knowledge, then the best that we can do is to support those organisations that are trying to reward truthfulness and embarrass misinterpretations such as 'Fullfact' (http://fullfact.org) - in the hope that a society that incentivises truthfulness in the long run will become a more truthful society. 


\section{References}

Alba, R., Rumbaut, R. G. \& Marotz, K. 2005. A distorted nation: Perceptions of racial/ethnic group sizes and attitudes toward immigrants and other minorities. Social Forces, 84, 901-919.

Baptist Union of Great Britain, the Methodist Church, the Church of Scotland \& the United Reformed Church 2013. The lies we tell ourselves: ending comfortable myths about poverty. London: Methodist Publishing.

Barabas, J. 2012. Social Security Knowledge. In: Lamdin, D. (ed.) Consumer Knowledge and Financial Decisions: Lifespan Perspectives.

Baumberg, B. 2014. Benefits and the cost of living: Pressures on the cost of living and attitudes to benefit claiming In: Park, A., Bryson, C. \& Curtice, J. (eds.) British Social Attitudes: the 31st Report. London: NatCen Social Research.

Baumberg, B., Bell, K., Gaffney, D., with Deacon, R., Hood, C. \& Sage, D. 2012. Benefits stigma in Britain. London: Elizabeth Finn Care/Turn2us.

Baumberg Geiger, B. In Press. The role of knowledge and 'myths' in the perceived deservingness of social security benefit claimants. In: van Oorschot, W. \& Roosma, F. (eds.) The social legitimacy of targeted welfare: Attitudes to welfare deservingness.

Beresford, P. 2013. Why welfare literacy is vital. The Guardian, 30/1/2013.

Blinder, A. \& Krueger, A. 2004. What does the public know about economic policy, and how does it know it? IZA Discussion Paper No. 1324. Bonn: The Institute for the Study of Labor (IZA).

Bolsen, T., Druckman, J. \& Cook, F. 2014. The Influence of Partisan Motivated Reasoning on Public Opinion. Political Behavior, 36, 235-262.

Bullock, J. G., Gerber, A. S., Hill, S. J. \& Huber, G. A. 2013. Partisan bias in factual beliefs about politics. NBER Working Paper No. 19080. Cambridge, MA: NBER (National Bureau of Economic Research).

Carpini, M. X. D. 2000. In search of the informed citizen: What Americans know about politics and why it matters. The Communication Review, 4, 129-164.

Carpini, M. X. D. \& Keeter, S. 1996. What Americans Know about Politics and Why it Matters, New Haven, CT, Yale University Press.

CNN. 2011. CNN Poll: Americans flunk budget IQ test. Available: http://politicalticker.blogs.cnn.com/2011/04/01/cnn-poll-americans-flunkbudget-iq-test $/$.

Converse, P. E. 1964. The Nature of Belief Systems in Mass Publics.”. In: Apter, D. (ed.) Ideology and discontent. New York: Free Press.

Cooke, G. 2013. On the Front Foot: Designing a Welfare Cap that Reforms Social Security. London: ippr (Institute of Public Policy Research). 
Coote, A. \& Lyall, S. 2013. "Strivers v. skivers: the workless are worthless". Mythbusters. London: nef (the new economics foundation) and the Tax Justice Network.

Dean, H. \& Taylor-Gooby, P. 1992. Dependency Culture: The Explosion of a Myth, Hemel Hempstead, Harvester Wheatsheef.

Duffy, B. 2009. The perils of perception. Ipsos MORI Understanding Society Summer 2009.

Dunn, A. 2010. The 'Dole or Drudgery' Dilemma: Education, the Work Ethic and Unemployment. Social Policy \& Administration, 44, 1-19.

Durant, J. R., Evans, G. A. \& Thomas, G. P. 1989. The public understanding of science.

Flvybjerg, B. 2001. Making Social Science Matter, Cambridge, Cambridge UP.

FullFact. 2011. Benefit fraud: Has DWP hotline increased prosecutions? Available: https://fullfact.org/factchecks/DWP fraud hotline success rate_prosecutions3167.

Gee, J., Button, M. \& Brooks, G. 2010. The financial cost of UK Public Sector Fraud: A less painful way to reduce public expenditure. Porstmouth: Center for Counter Fraud Studies (CCFS), University of Portsmouth.

Golding, P. \& Middleton, S. 1982. Images of welfare: press and public attitudes to welfare, Worcester, Billing \& Sons Limited.

Herda, D. 2010. How many immigrants? Foreign-born population innumeracy in Europe. Public Opinion Quarterly, 74, 674-695.

Hills, J. 2014. Good times, bad times: The welfare myth of them and us, Bristol, Policy Press.

HM Government 2014. Fraud and error in the benefits system: Government Response to the Committee's Sixth Report of Session 2013-14 - Work and Pensions Committee. London: House of Commons.

Jacobs, L. R. \& Shapiro, R. Y. 1999. Myths and misunderstandings about public opinion toward Social Security: Knowledge, support, and reformism, Century Foundation.

Kellner, P. 2014. Welfare tourism: crisis, what crisis? Available:

https://yougov.co.uk/news/2014/01/13/welfare-tourism-crisis-what-crisis/ [accessed 21/7/2015].

Kellner, P. 2015. The truth about welfare. Prospect.

Kelly, M. 2008. Public attitudes to child poverty [research summary]. London: DWP (Department of Work and Pensions).

Kuklinski, J. H., Quirk, P. J., Jerit, J., Schwieder, D. \& Rich, R. F. 2000. Misinformation and the Currency of Democratic Citizenship. The Journal of Politics, 62, 790-816. 
Kuklinski, J. H., Quirk, P. J., Schwieder, D. W. \& Rich, R. F. 1998. " Just the Facts, Ma'am": Political Facts and Public Opinion. The Annals of the American Academy of Political and Social Science, 143-154.

Kuziemko, I., Norton, M. I. \& Saez, E. 2015. How Elastic Are Preferences for Redistribution? Evidence from Randomized Survey Experiments. American Economic Review, 105, 1478-1508.

Liebman, J. B. \& Luttmer, E. F. 2012. The Perception of Social Security Incentives for Labor Supply and Retirement: The Median Voter Knows More Than You'd Think. Tax Policy and the Economy, 26, 1-42.

Lindsay, C. \& McQuaid, R. W. 2004. Avoiding the 'McJobs': Unemployed Job Seekers and Attitudes to Service Work. Work, Employment \& Society, 18, 297 319.

Liu, M. \& Wang, Y. 2014. Data collection mode effects on political knowledge. Survey Methods: Insights from the Field [Online]. Available: http://surveyinsights.org/?p=5317.

Lupia, A. 2006. How elitism undermines the study of voter competence. Critical Review, 18, 217-232.

MacDonald, R., Shildrick, T. \& Furlong, A. 2013. In search of 'intergenerational cultures of worklessness': Hunting the Yeti and shooting zombies. Critical Social Policy 34, 199-220.

MacDonald, R., Shildrick, T. \& Furlong, A. 2014. 'Benefits Street' and the Myth of Workless Communities. Sociological Research Online, 19, 1.

Macmillan, L. 2011. Measuring the intergenerational correlation of worklessness, Centre for Market and Public Organisation (CMPO), University of Bristol.

Martinez, M. D., Wald, K. D. \& Craig, S. C. 2008. Homophobic innumeracy? Estimating the size of the gay and lesbian population. Public Opinion Quarterly, 72, 753-767.

Prior, M. \& Lupia, A. 2008. Money, Time, and Political Knowledge: Distinguishing Quick Recall and Political Learning Skills. American Journal of Political Science, 52, 169-183.

Sanders, D., Clarke, H. D., Stewart, M. C. \& Whiteley, P. 2007. Does mode matter for modeling political choice? Evidence from the 2005 British Election Study. Political Analysis, 15, 257-285.

Schwarz, N. 1999. Self-reports: How the questions shape the answers. American Psychologist, 54, 93-105.

Slater, T. 2012. The Myth of "Broken Britain”: Welfare Reform and the Production of Ignorance. Antipode, 46, 948-969.

Sundberg, T. 2014. Attitudes to the Welfare State: A Systematic Review Approach to the Example of Ethnically Diverse Welfare States. Sociological Research Online, 19, 28. 
Taber, C. S., Cann, D. \& Kucsova, S. 2009. The Motivated Processing of Political Arguments. Political Behavior, 31, 137-155.

Taunton-Collins, G. 2013. Busting welfare myths. Available: http://www.adamsmith.org/research/thinkpieces/bustingwelfaremyths/.

Taylor-Gooby, P., Hastie, C. \& Bromley, C. 2003. Querulous citizens: welfare knowledge and the limits to welfare reform. Social Policy and Administration, 30, 31-46.

TNS Opinion \& Social 2010. Europeans' knowledge of economic indicators. Special Eurobarometer 323. Brussels: TNS for the European Commission.

TUC 2013. Support for benefit cuts dependent on ignorance, TUC-commissioned poll finds [press release]. London: TUC (Trades Union Congress).

Viaene, S. \& Dedene, G. 2004. Insurance Fraud: Issues and Challenges. The Geneva Papers on Risk and Insurance, 29, 313-333. 